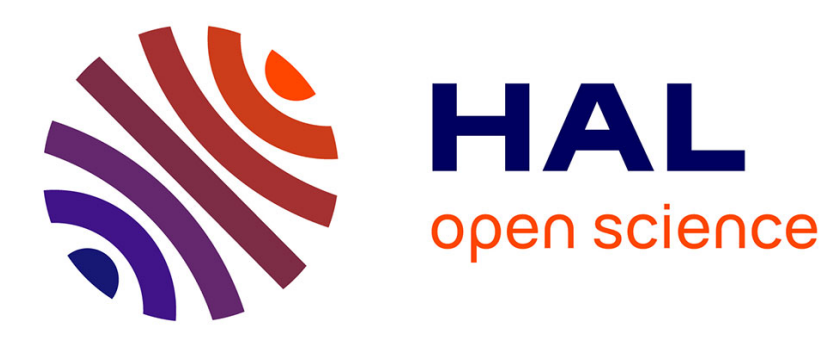

\title{
Priming syntactic ambiguity resolution in children and adults
}

\author{
Naomi Havron, Camila Scaff, Maria Julia Carbajal, Tal Linzen, Axel \\ Barrault, Anne Christophe
}

\section{- To cite this version:}

Naomi Havron, Camila Scaff, Maria Julia Carbajal, Tal Linzen, Axel Barrault, et al.. Priming syntactic ambiguity resolution in children and adults. Language, Cognition and Neuroscience, 2020, 35 (10), pp.1445-1455. 10.1080/23273798.2020.1797130 . hal-03099573

\section{HAL Id: hal-03099573 \\ https://hal.science/hal-03099573}

Submitted on 6 Jan 2021

HAL is a multi-disciplinary open access archive for the deposit and dissemination of scientific research documents, whether they are published or not. The documents may come from teaching and research institutions in France or abroad, or from public or private research centers.
L'archive ouverte pluridisciplinaire HAL, est destinée au dépôt et à la diffusion de documents scientifiques de niveau recherche, publiés ou non, émanant des établissements d'enseignement et de recherche français ou étrangers, des laboratoires publics ou privés. 


\section{Priming syntactic ambiguity resolution in children and adults}

Naomi Havron ${ }^{1}$, Camila Scaff ${ }^{1,4}$, Maria Julia Carbajal ${ }^{1}$, Tal Linzen ${ }^{2}$, Axel Barrault ${ }^{1,3}$, Anne

Christophe $^{1}$

naomi.havron@mail.huji.ac.il

carbajalmjulia@gmail.com

camiscaff@hotmail.com

tal.linzen@gmail.com

barrault.axel@gmail.com

anne.christophe@ens.fr

This is a preprint of an accepted paper, one can cite it as:

Havron, N. Scaff, C., Carbajal, J.M., Linzen, T., Barrault, A. \& Christophe, A. (in press).

Priming syntactic ambiguity resolution in children and adults. Language, Cognition and

Neuroscience.

Affiliations: ${ }^{1}$ École normale supérieure, CNRS, EHESS, PSL University, Paris, France.

${ }^{2}$ Department of Cognitive Science, Johns Hopkins University, Baltimore, USA

${ }^{3}$ Laboratoire Parole et Langage, Aix-Marseille Université, Aix-en-Provence, France

${ }^{4}$ Paris Diderot University, Paris, France

Corresponding author information: Naomi Havron, phone: +972512056915 , Fax: +33144322630 , email:

naomi.havron@mail.huji.ac.il 


\begin{abstract}
Adults use their recent experience to disambiguate ambiguous sentences: Structures that have recently been primed are favored in the resolution of different types of ambiguity, an example of structural priming. Research on children's use of recent information for disambiguation is scarce. Using a forced-choice task with a tablet, we asked whether 5-6-year-old French-speaking children could also be primed in the resolution of attachment ambiguities, as well as whether listeners are affected by the proportion of primes of each structure, and whether priming is cumulative. We found that both children and adults can be primed, and are sensitive to the proportion of structures in the input, and that priming effects cumulate as the experiment progresses. This is the first study showing priming of ambiguous sentences at 5-6 years, suggesting that children, like adults, use recent experience as a source of disambiguating information.

\section{Keywords}

Adaptation, Priming, Ambiguity, Language, Children
\end{abstract}




\section{INTRODUCTION}

Language contains ambiguities at multiple levels. To name a few, language users can encounter lexical ambiguities, such as in the case of homophones (e.g., "the baby flies" as referring to an airborne baby vs. "the baby flies" as referring to little insects); or syntactic ambiguities, such as in cases where two different parses of the same sentence are possible (e.g., "Someone saw the servant of the actress who was on the balcony" - who was on the balcony: the actress or the servant?). Adults are able to process these and other types of ambiguities by rapidly utilizing and integrating multiple sources of information, such as verb bias, contextual constraints, and prosody (Gibson \& Pearlmutter, 1998). Learning to process a language thus entails learning to utilize these sources of information to converge on one of several possible meanings or interpretations, preferably the one intended by the interlocutor (MacDonald, Pearlmutter, \& Seidenberg, 1994).

Children begin to use different sources of disambiguating information at different ages. For example, relative to adults, even 8-12-year-old children have difficulty using semantic plausibility to disambiguate ambiguous sentences (e.g., in "While the boy drank the girl ate some ham" - "the girl" is implausible as a direct object of the subordinate verb, Traxler, 2002). Verb bias - the probability that a verb will appear with one construction relative to others - can be used by both 45-year-old children and adults to interpret ambiguous sentences such as "tickle the pig with the fan" or "surprise the pig with the fan" (tickle is a verb that is more biased towards an instrument use than surprise, Snedeker \& Trueswell, 2004). However, in the same paper, and unlike adults, 4-5-year-old children could not use extralinguistic context to interpret such ambiguous sentences (e.g., whether there were two pigs in the scene, only one of which had a fan, Snedeker \& Trueswell, 2004). This suggests that the ability to use extra-linguistic context develops later than the ability to use verb bias (see also Weighall, 2008). In contrast, the ability to use other sources of disambiguating information may develop quite early. Children as young as three years old can already use gestures to disambiguate lexical ambiguities (e.g., "bat", Kidd \& Holler, 2009), and

prosody has been found to facilitate ambiguity resolution in the case of noun-verb homophones by infants as young as 20 months (de Carvalho, Dautriche, Lin, \& Christophe, 2017). In other words, some sources of disambiguating information have a longer developmental time-course than others, with children learning to combine them as they grow older.

Here, we focus on one important source of information for ambiguity resolution - recent experience: Whether a specific structure was recently used or not. Recent experience has been 
found to affect adults' processing of ambiguities, such that structures that have recently been encountered are favored in the resolution of ambiguity, an effect known as structural priming (Boudewyn, Zirnstein, Swaab, \& Traxler, 2014; Branigan, Pickering, \& McLean, 2005). The effect of recent experience on the processing of ambiguous sentences has hardly been studied in children. Studies on syntactic priming in children would suggest that children are able to use recent experience for language production (where no ambiguitiy is involved, Peter, Chang, Pine, Blything, \& Rowland, 2015; Rowland, Chang, Ambridge, Pine, \& Lieven, 2012; Shimpi, Gámez, Huttenlocher, \& Vasilyeva, 2007) - but evidence for priming in comprehension is scarce, and there are very few studies showing priming in global-ambiguity resolution, as will be discussed below.

Priming in children's comprehension was notably tested in one study (Thothathiri \& Snedeker, 2008). Thothathiri and Snedeker showed that it is possible to prime 3-4 year-old children's comprehension by manipulating their expectation to encounter either a double-object or a prepositional-object construction. Children heard sentences such as "Give the bird the dog bone" or "Give the birdhouse to the sheep", while watching a display which included the bird, the dog bone, the birdhouse and a distractor. Thothathiri and Snedeker measured the proportion of looks to the bird and the birdhouse before the disambiguating information was heard, and found that children who were primed with a double-object construction were more likely to look at the bird rather than the birdhouse, than children who were primed with a prepositional-object construction. In other words, children were primed to expect the noun phrase following the verb to be the recipient rather than the direct object of the verb. Importantly, Thothathiri and Snedeker found that children show structural priming even when the verb is not repeated between prime and target, which suggests that abstract structural priming in children's comprehension is not wholly dependent on lexical overlap. Two additional studies tested priming in comprehension but found mixed results (Brandt, Nitschke, \& Kidd, 2017; Qi, Yuan \& Fisher, 2011). We return to these studies in detail below, because they are directly relevant to our design.

The present study explores the effect of recent syntactic experience on globally-ambiguous sentences, that is, sentences that remain open to both interpretations even after the full sentence has unfolded. This allows participants to construct their own interpretation of the sentence, to its very end, rather than forcing them to access a specific interpretation using disambiguating lexical material. This also enables us to further explore cumulative priming, as we will describe below. 
In the current study, we ask whether children and adults are affected by their recent linguistic experience in interpreting sentences that contain prepositional-phrase attachment ambiguities. Prepositional-phrase attachment ambiguities arise when a prepositional phrase can modify either the verb or the object noun in a sentence, as in, for example: "the girl is tickling the baby with the brush." In one interpretation of this sentence, the girl is using a brush to tickle the baby. Here, the prepositional phrase "with the brush" modifies "tickling", and therefore attaches to the verb phrase. We will refer to this interpretation as a verb-attachment interpretation. In the other interpretation, the baby being tickled is the one holding the brush. Here, "with the brush" modifies the noun phrase "the baby". We will refer to this as a noun-attachment interpretation. Children were previously found to be able to use prosody and lexical biases to resolve these ambiguities (Snedeker \& Yuan, 2008). Additionally, recent experience of a resolution of this ambiguity towards one of these interpretations has been shown to affect interpretation of these ambiguities in adults (Boudewyn et al., 2014; Branigan et al., 2005) - but this has never been shown in young children.

Brandt, Nitschke, and Kidd (2017) tested whether children can be primed in their interpretations of globally-ambiguous German object relative clauses - which can be interpreted as agent-first or patient-first (e.g., Wo ist die Krankenschwester, die die Malerin umarmt? Can be understood as either "where is the nurse that the painter is hugging?" or "where is the nurse that is hugging the painter?"). However, they only found an effect of priming in nine-year-old, but not six-year-old children. They concluded that children in the younger age group might not have developed a fully abstract representation of object relative clauses yet, or were unwilling to accept the priming of the dispreferred interpretation. The current study tries to overcome these challenges by, first, choosing a different construction, which might be easier for young children to process, as it had been shown previously that 3-5-year-old (English-speaking) children accept both interpretations of these types of sentences, even when the prosody is neutral (e.g., Zimmer, 2017). Second, by using a tablet device, where children are asked to touch the image that corresponds to the sentence they have heard, which might induce them to be more willing to accept the dispreferred interpretation (by creating more commitment to the prime when a tactile response has to be given).

Qi, Yuan and Fisher (2011) tested English-learning five-year-old children on prepositionalphrase attachment ambiguities similar to the ones we use in the current study. They gave children 
extensive training with 'with-sentences' such as "point at the tiger with the sharp teeth" or "point at the tiger with the magic sword", and then tested them behaviorally and using an eye-tracker on sentences which were ambiguous as to whether the final object attached to the verb or to the noun. For example, for the sentence "point to the pig with the flower" the display contained a pig with a flower and a flower which the child could use to point to the pig. Results were mixed. Behaviorally, the children showed no effect of training, and the eyetracking measures showed an effect of training in only some of the analyses. Thus, our study might be able to shed more light on these mixed results.

In addition to an effect of priming on children's interpretation of globally-ambiguous sentences, our design is meant to answer two additional questions relating to the way recent experience affects both children and adults. It has previously been shown that adults and children show an effect of cumulative priming (Branigan \& Messenger, 2016; Kaschak , Kutta, \& Schatschneider, 2011; Kaschak, Kutta, \& Jones, 2011), that is, they show long-lasting and cumulative effects of experience, whereby the more prime instances a participant witnesses, the stronger the priming effect. These effects have been claimed to implicate long-term changes to the syntactic system, such that the effect of priming is unaffected by the time lag between primes (Bock \& Griffin, 2000; Chang, Dell, \& Bock, 2006). We ask whether children also adapt their expectations to the proportion of prime sentences of a particular type in their input, thus showing more than just sensitivity to the immediate prime.

We use a design with three different conditions to manipulate the relative proportion of the two possible interpretations (noun-attachment and verb-attachment primes). One group is primed with noun-attachment primes throughout the experiment (100\% noun-attachment); another group is primed with verb-attachment primes throughout the experiment ( $0 \%$ noun-attachment); and the third with alternating verb-attachment and noun-attachment primes (alternating primes). Based on the adult literature, we expect that both children and adults will be sensitive to the distribution of structures in their input (Jaeger \& Snider, 2013), and will therefore be more likely to select the noun-attachment interpretation when the proportion of noun-attachment primes is greater. Similarly, we could expect that the choice of noun-attachment interpretation will be less likely when the proportion of verb-attachment primes in the input is larger. However, previous studies have shown that the effect of syntactic priming is larger for less frequent structures. If this is also the case in the current study, then verb-attachment primes, which represent the more frequent and 
likely interpretation (see Method section), might show a smaller priming effect. This is consistent with the view of structural priming as error-driven implicit learning, since more surprising primes should induce bigger changes to structural predictions in order to accommodate this deviant evidence (see for example Kaschak et al., 2011; Peter et al., 2015).

We also explore cumulative priming in an additional analysis. Since the ambiguities participants are facing are global ambiguities, that is, they are never disambiguated and both interpretations remain possible after the sentence has unfolded, participants are expected to differ in how often they select one interpretation over the other. The design of our study makes participants blind to the type of trial they are completing. Unlike in production studies, where it is clear to the child which trials are produced by the experimenter and which are produced by themselves (e.g., Branigan \& Messenger, 2016), here participants are asked to choose which image best corresponds to the sentence they heard. Whether the sentence is a prime, a target or a filler, participants are always trying to fit the speaker's intention. Thus, each one of their choices, on both prime and target sentence, can further prime them in their future interpretations. In this analysis we use a measure of cumulative experience (the number of interpretations of one structure across all previous prime and target trials) to predict the likelihood of selecting this interpretation again.

We test both children and adults, and expect both groups to show all three hypothesized effects: overall syntactic priming, effect of the proportion of primes and cumulative priming. We have no prediction as to whether children and adults will differ in the size of any of these effects. If children are able to understand the sentences - that is, process the error-signals of the primes to the same extent as adults, they should show the same priming effects as adults. They might even show a bigger priming effect, as would be predicted by error-driven learning accounts, if children's representations are not as robust as adults, and are thus more easily changed in the face of new evidence. Indeed, it was previously found that the effect of mismatch between prime and verb bias is stronger in children than in adults (Peter et al., 2015). However, we are prepared for the possibility that children are less likely than adults to understand the prime sentence or to accept it as a possible interpretation. In that case they might show smaller priming effects than adults. A complete absence of a priming effect in children, on the other hand, could be interpreted as an inability to use recent structural information in the interpretation of globally ambiguous sentences, thus suggesting that this ability takes longer to develop, compared to the use of other sources of 
information, such as prosody. Alternatively, like in Brandt et al. (2017), such an outcome might just be the result of the complexity of the structure we have chosen.

\section{METHOD}

While we originally preregistered the study on the OSF, we have since become convinced that our design was inappropriate to test our original hypothesis (relating the effect of adapted surprisal and priming, see Jaeger \& Snider, 2012). The preregistration thus bears little relevance to the current predictions and analyses, but for the sake of transparency, we have made it, and the results of the preregistered analysis available on the OSF. The link also includes all study materials, results and analysis scripts: https://osf.io/4rnpy/?view_only=86c3a7c291ae461fa47ca6874754fffb

\section{Participants}

5-6 year-old French-speaking children from medium to high socio-economic schools in Paris were tested in a quiet room at their preschool. Parental consent was obtained before testing. After applying our exclusion criteria described below, we were left with 81 child-participants (mean age 69 months, 55 girls). 80 university students were tested at our lab. They received $€ 2$ for their participation.

Exclusion. We excluded bilinguals ( 2 children), children who chose alternating responses throughout (left side - right side - left side, etc., 2 children), and one child who, by her own admission, chose wrong answers on purpose - just to see what happens ${ }^{1}$. Two pairs of items in two of the $100 \%$ noun-attachment prime lists were programmed incorrectly (participants saw a prime instead of a target in one target trial); this was fixed mid-testing. These trials were removed only for these first participants. We also removed target trials where participants made the wrong choice on a prime trial (e.g., when the sentence was "the girl is tickling the baby with the brush" they chose a picture of a girl watching a baby paint rather than tickling it with a brush - these trials correspond to 66 trials for children, and 5 trials for adults $-7 \%$ of trials for children and $0.6 \%$ of trials for adults). We removed six children's trials for which the experimenter indicated in the log that the child was distracted. We calculated the percentage of correct responses on all unambiguous

\footnotetext{
${ }^{1}$ Including these three children in the sample does not change our pattern of results.
} 
trials (training, filler and prime sentences): None of the remaining participants had an accuracy of less than $80 \%$; consequently, no participant was removed due to low accuracy.

\section{Materials}

11 prime-target pairs were constructed. All prime and target sentences included two characters and an object, using the French preposition avec ("with"). For example, la fille chatouille le bébé avec le pinceau, "the girl is tickling the baby with a brush", is ambiguous in French (as it is in English) as to which character is holding the object. All sentences were ambiguous with respect to whether the prepositional phrase attached to the verb or the noun. We also had six unambiguous filler sentences and three practice items, which did not include the preposition avec. Prime and target sentences shared the same verb, as a recent meta-analysis found overall larger priming effects when lexical overlap exists (Mahowald, James, Futrell, \& Gibson, 2015, though lexical overlap might be less important for children, see: Peter, Chang, Pine, Blything, \& Rowland, 2015, cf. Branigan, \& McLean, 2016). We counterbalanced across participants which of the sentences served as the prime and which served as the target. We created 16 pseudo-random lists, four for the $100 \%$ noun-attachment primes condition, four for the $0 \%$ noun-attachment primes condition, and eight for the alternating condition. While this complicated the interpretation of order effects (since item identity and trial order are partially confounded ${ }^{2}$ ), the app we used to run the experiment did not permit randomization for each participant, but instead necessitated fixed lists.

On each trial, two images were presented side by side, and then a cartoon girl ("Mandy") appeared in the space between them. When the participant touched Mandy, she would say the sentence, and the participant was asked to touch the image that corresponded to it. The sentences Mandy said were recorded by a native speaker of French (the last author), who used a prosodic contour meant to be consistent with both the noun-attachment and verb-attachment interpretations. To compute the overall bias of our items in French, we ran an online survey with 77 adult native French speakers. The respondents received only target sentences, that is, they were never primed.

\footnotetext{
${ }^{2}$ Some sentences are more conductive to noun-attachment interpretation than others. For example, "the boy is kissing the girl with her/his tedding bear" is a better noun-attachment candidate than "the cat is hitting the mouse with the cheese". In order to control for this variable, we used counterbalanced lists. An equal number of participants saw the first sentence at the beginning of the experiment as those who saw it towards the end. However, precise models of how the number of previous primes affected a specific target might be noisy, because which primes were preceding that specific target was not fully randomized.
} 
Each participant heard only one instance of the same verb - that is, 11 possible sentences rather than the full set of 22. They were asked, for each pair of images, which of the images fit best the sentence they had heard. Participants chose the noun-attachment interpretation $15.29 \%$ of the time. Items were not equi-biased, and their bias ran from 40\%-100\% in favor of the verb-attachment interpretation (all items but one were biased towards the verb-attachment interpretation). See OSF link for the recorded sentences and images.

In the actual experiment, on prime trials, only one of the images corresponded to the sentence, while the other image (the foil) displayed the same characters and the same object but not the same action, and thus clearly did not match the sentence. In target sentences, both images matched the sentence (see Figure 1 for a sample prime-target pair). The application used to deliver the stimuli and gather responses is available on github: https://github.com/alecristia/mandy_newplugin.

a)
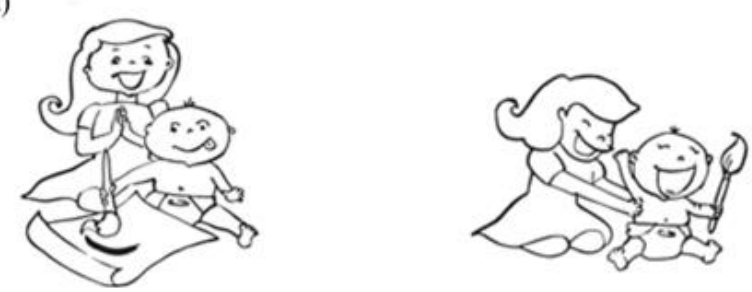

b)
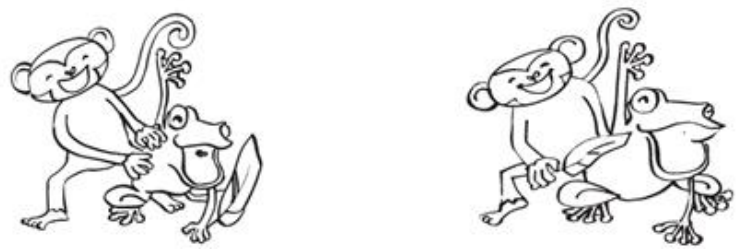

Figure 1: example of a prime-target pair

a) A prime trial: La fille chatouille le bébé avec le pinceau ("the girl is tickling the baby with the brush"). Since the image on the left does not match the sentence, the participant will be forced to select the image on the right, which is the noun-attachment interpretation (the girl is tickling a baby who is holding a brush). b) A target trial: Le singe chatouille la grenouille avec la plume ("the monkey is tickling the frog with the feather"). On the left, the noun-interpretation (the monkey is tickling a frog who is holding a feather), and on the right a verb-attachment interpretation (the monkey is using a feather to tickle the frog). Both images match the sentence. 


\section{Design}

Participants were randomly assigned to one of three input conditions: $100 \%$ noun-attachment primes (no verb-attachment primes), 0\% noun-attachment primes (all verb-attachment primes), and an alternating primes condition (every two noun-attachment prime trials were separated by exactly one verb-attachment prime trial, and possibly a filler trial). There were 19 children and 20 adults in the $100 \%$ noun-attachment condition; 22 children and 20 adults in the $0 \%$ nounattachment condition; and 40 children and 40 adults in the alternating primes condition. Running twice as many subjects in this condition was necessary for counterbalancing (i.e., 20 children began with a verb-attachment prime, and 20 with a noun-attachment prime).

\section{Procedure}

Children were tested individually in a quiet room in their school, wearing headphones, with an experimenter who could not see the display on the tablet (except in the training phase). They were asked to look at the two images, then touch Mandy, then touch the image she was talking about. They had three practice trials where there was only one correct answer. For these trials only, they were also asked to describe the images before touching Mandy. In these trials, if a child made an error, the experimenter explained why the response was incorrect. After the training phase, the children were told that they would now start the real game. Adults followed the same procedure in our laboratory or in a quiet room in the university. The entire task lasted about 20-25 minutes.

\section{RESULTS}

\section{Overall priming}

We first examined whether there was an overall priming effect for the alternative condition only. We ran a logistic mixed effect model using the software $R$ (R core team, 2017) and the packages lme4 (Bates, Maechler, Bolker, \& Walker, 2015) and lmerTest (Kuznetsova, Brockhoff, \& Christensen, 2017). We used prime type (sum coded) and age group (sum coded), as well as an interaction between the two, as independent variables - to predict the likelihood of selecting a noun-attachment interpretation. The random effect structure was fitted using a parsimonious model, a principal component analysis procedure recommended in Bates, Kliegl, Vasishth, and 
Baayen $(2015)^{4}$. We found a reliable priming effect $(\beta=-1.92, \mathrm{SE}=.29, \mathrm{p}=.018)$. There was no effect of age group nor an interaction.

In table 1 we present the effect size for the different groups, and fig. 2 shows the distribution of results. Inspection of the table shows an overall larger effect size for children than for adults, though the interaction between the effect of prime type and age group was not significant, and we therefore cannot deduce that the effect is indeed stronger in children.

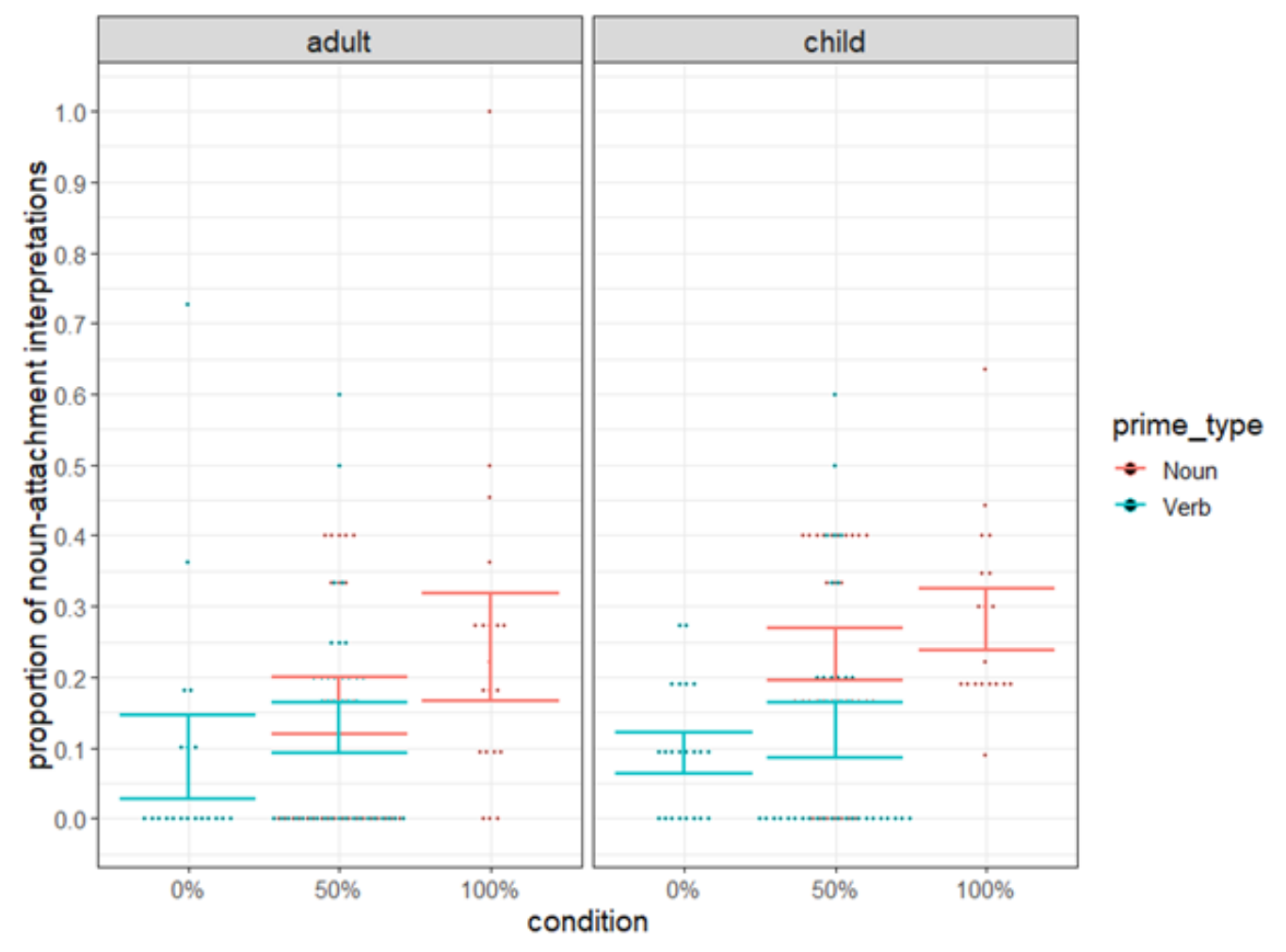

Figure 2: Proportion of noun-attachment interpretation by age, condition and prime type (each dot represents the mean prroportion of noun-attachment per participant and prime type, error bars represent 1.5 standard errors from the mean).

\footnotetext{
${ }^{4}$ That is, we first fit a maximal model including all possible random intercepts and slopes, and then ran a principal component analysis of the random effects structure to determine the number of variance components and correlation parameters supported by the data (using function rePCA from the package RePsychLing, Baayen, Bates, Kliegl, \& Vasishth, 2015). This function identifies the most complex model supported by the data, and then, to simplify the model, relies on comparisons of goodness of fit of nested models with likelihood ratio tests (LRTs). We chose this procedure rather than the more prevalent use of the maximal effect structure allowing the model to converge (Barr, Levy, Scheepers, \& Tily, 2013), because this procedure allows for a robust random effect structure without including unnecessary random effects thereby losing power. Indeed, a maximal random effect structure did not converge with our analysis, which is often the case with complex random effect structures.
} 
Table 1: Means (SDs) and Cohen's ds for the proportion of noun-attachment interpretation choices after different primes

\begin{tabular}{lccc} 
& Noun-attachment prime & Verb-attachment prime & Cohen's d and CI \\
\hline Adults & $0.187(0.195)$ & $0.114(0.158)$ & $0.491[0.123,0.860]$ \\
Children & $0.248(0.148)$ & $0.114(0.143)$ & $0.921[0.542,1.299]$
\end{tabular}

\section{Proportion of structures in the input}

Next, we examined our second hypothesis, that is, that participants will be sensitive to the proportion of primes of each type in the input. We expected participants to choose more nounattachment interpretations in the $100 \%$ noun-attachment primes condition than in the alternating condition. Likewise, we expected participants to choose more noun-attachment interpretations in the alternating primes condition than in the $0 \%$ noun-attachment primes condition. To examine this hypothesis, we ran two logistic linear mixed effects models. In the first model we compared the alternating primes and 100\% noun-attachment primes conditions when taking into account only targets that were preceded by a noun-attachment prime. Because the $0 \%$ noun-attachment condition does not contain any noun-attachment primes, it is not included in this model (i.e., because it is not possible to use test trials with verb-attachment primes in this comparison). We used condition (sum coded) and age group (sum coded), as well as an interaction between the two, as independent variables to predict the likelihood to select a noun-attachment interpretation. Here too, we ran a principal component analysis on the random effects structure. The second model was identical, except that it focused on responses following a verb-attachment prime in the alternating primes condition vs the $0 \%$ noun-attachment primes condition (again, the $100 \%$ condition is excluded from this comparison because it contains no verb-attachment primes).

We found a small condition effect for noun-attachment primes $(\beta=0.34, \mathrm{SE}=0.17, \mathrm{p}=$ .046). Target trials that were preceded by a noun-attachment prime were more likely to produce noun-attachment responses in the $100 \%$ noun-attachment primes condition than in the alternating primes condition. The effect of condition was not significant for verb primes $(\beta=-0.07, \mathrm{SE}=$ $0.3, p=.83)$. There was no effect of age group nor an age group by condition interaction for either model. See table 2 for means, SDs and Cohen's ds, and figure 2 for a visualization of the 
results for the different conditions and prime types (created using package ggplot2 in R, Wickham, 2016).

\section{Cumulative priming effects}

As a next step we examined whether there was an effect of cumulative priming on response choice. To examine this question we added the number of previous noun-attachment choices as a continuous variable to our models - this included noun-attachment choices on both prime and target sentences. Thus, our final model used prime type (sum coded) and age group (sum coded), as well as an interaction between the two, with the addition of the cumulative number of nounattachment choice in both prime and target sentence as independent variables. The random effect structure was fitted using a parsimonious model, as in all models above. We again ran this model only for the alternating condition, because we cannot include all three conditions in the same model, and if we ran a model comparing the $0 \%$ and $100 \%$ separately from the alternating condition, the effect of cumulative priming and condition would be confounded. We found that cumulative priming had a significant effect on interpretation $(\beta=0.27, \mathrm{SE}=.06, \mathrm{p}<.0001)-$ the more noun-attachment interpretations participants chose, the more likely they were to choose a noun interpretation again. The effect of trial type was still significant after controlling for this effect $(\beta=-0.91, \mathrm{SE}=.39, \mathrm{p}=.02)$, that is, there is still a significant effect of priming in a model that includes both trial type (measuring syntactic priming), and cumulative priming. None of the other effects were significant.

Although the interaction between age group and prime type was not significant, since our hypothesis relates especially to children, we wanted to make sure that the effect also exists when we run the same model only on children. Like in the model that includes both children and adults, cumulative priming was a significant predictor for the model that included only children $(\beta=0.25, \mathrm{SE}=.11, \mathrm{p}=.02)$. Prime type (immediate priming) was not significant after controlling for cumulative priming $(\beta=-0.76, \mathrm{SE}=.45, \mathrm{p}=.09)$. 


\section{DISCUSSION}

The current study explored adults' and children's use of their recent experience, the distribution of syntactic structures in the input, to interpret ambiguous sentences. We asked whether children and adults show overall structural priming effects when interpreting ambiguous sentences. Second, whether they are taking into account the proportion of the two syntactic structures in their input. And third, whether interpretations were affected by the sum of participants' previous choices on both prime and target trials, thus exemplifying cumulative priming.

We found an overall priming effect for both children and adults, with no interaction between age group and priming. The results for adults replicate previous studies (Boudewyn et al., 2014; Branigan et al., 2005). For children, this is the first piece of evidence that children as young as five years can be structurally primed to select different interpretations for the same sentence (see Qi, Yuan \& Fisher, 2011 for mixed results - note that their participants were, on average, nine months younger than ours). One previous study that primed interpretation of globally ambiguous sentences in children found an effect of priming in nine-year-old but not six-year-old children (Brandt et al., 2017). The authors explained these results by suggesting that children in the younger age group might not have developed a fully abstract representation of object relative clauses yet, or were unwilling to accept priming of the dispreferred interpretation. One possible reason why we were able to prime young children in the current study, might therefore be that the ambiguous structures we used were simpler, as it had been shown previously that even 3-5-year-old children can accept both interpretations of these types of sentences (Zimmer, 2017). Therefore, our result is consistent with Brandt and colleagues' suggestion that six-year-old children in their study were not primed because they had not yet fully developed representations of both options for disambiguating the sentences.

The difference between our results and theirs could also be explained by methodological differences between the designs. Brandt and colleagues compare primed trials to a baseline with no priming, while we compare priming with one interpretation to priming with the other one which may give rise to bigger differences since the effect of one prime type would be positive and of the other prime type would be negative - resulting in a larger difference. Also, in our study there was always lexical overlap between the verb of the prime and the target sentence (while in Brandt and colleagues there was an overlap of the noun but not the verb). When the verb overlaps between the prime and target sentence, this can give rise to a lexical boost, an increase in the priming effect. 
While the lexical boost is a common phenomenon in adults, there are mixed results on whether children show it as well (e.g., Branigan, \& McLean, 2016; Morris \& Scheepers, 2015 found an effect, but Peter, Chang, Pine, Blything, \& Rowland, 2015; Rowland, et al. 2012 did not). Lexical overlap at the verb has been studied more than lexical overlap at the noun. While two previous studies found a lexical boost in children when there is a noun overlap (Branigan, McLean, \& Jones, 2005; Cleland \& Pickering, 2003); there are no studies comparing the size of the lexical boost in nouns and in verbs in children, and verb-overlap might (or might not) show a larger lexical boost. Note, that while all prime-target pairs had lexical overlap at the verb, our effects cannot be fully explained as a result of a lexical rather than structural priming: the influence of participants' previous experience in the experiment (cumulative priming) can only arise if priming is not only a result of the last prime, but also of previous primes (which did not share a verb with the target). In fact, children did not show an immediate priming effect (where the prime and target sentence shared a verb) when controlling for this cumulative priming effect. While our results point to priming even in the absence of lexical overlap, our design does not allow us to conclude whether our participants showed a lexical boost or not. Future studies should also manipulate lexical overlap to shed more light on its existence (or lack thereof) in children - as the lexical boost itself cannot be explained by error-driven learning, and has been proposed to operate though a different route (see for example Chang, Dell, \& Bock, 2006; Reitter, Keller, \& Moore, 2011).

Our results therefore show that children can be primed not only to choose a specific syntactic structure in production as was previously found (e.g., Peter, Chang, Pine, Blything, \& Rowland, 2015; Rowland, Chang, Ambridge, Pine, \& Lieven, 2012), but also to interpret a sentence in two different ways. A previous study has already shown that it is possible to syntactically prime children's comprehension - however, this study focused on how children's expectations for a specific structure impacted their lexical access at a point of local ambiguity (Thothathiri \& Snedeker, 2008), while we tested children's interpretation of globally ambiguous sentences. The priming effect we show could help children understand the meaning behind their interlocutor's globally ambiguous utterances, assuming speakers are relatively stable in their structural choices during a conversation. Thus, children would be able to not only predict their interlocutor's utterances so as to speed up and support correct processing, but also to interpret ambiguous utterances after these sentences have fully unfolded. 
The second question we examined was convergence on the proportion of structures in the input. We hypothesized that both children and adults would show sensitivity to the distribution of syntactic structures in the input. Consistent with this hypothesis, we observed that children and adults were more likely to select a noun-attachment interpretation in the all-noun-attachment primes condition than in the alternating condition (this effect, however, was small and should be replicated to examine if it is robust). In the comparison between the all-verb-attachment primes condition and the alternating condition, participants did not differ in their likelihood to select a verb-attachment interpretation. This finding is in line with previous studies on priming of the dative alternation: The more frequent prime type (double-object, in English) usually shows overall weaker priming (Jaeger \& Snider, 2013; Kaschak, \& Kutta, 2011; Kaschak, Kutta, \& Jones, 2011). In the present study, similarly, the more frequent interpretation (verb-attachment) was less impacted by priming effects.

To assess cumulative priming, we performed additional analyses. We used the number of interpretations of one structure across all previous prime and target trials to predict the likelihood of selecting this interpretation again. Cumulative priming defined in this way was a significant predictor of participants' choice, and this predictor was in fact stronger than the effect of simple priming. This finding joins other studies which have found cumulative priming effects in adults (e.g., Kaschak, \& Kutta, 2011; Kaschak, Kutta, \& Jones, 2011) and extends them to children. This is particularly important, as it has been proposed that priming experiments may capture effects relevant to language acquisition (e.g., Bock \& Griffin, 2000; Brooks \& Tomasello, 1999; Havron, de Carvalho, Fiévet, \& Christophe, 2019).

In the current study, we focus on recent experience as a source of information for disambiguating sentences. The question of whether children can use recent experience to adapt their interpretations of prepositional-phrase attachment ambiguities is especially interesting in light of Snedeker and Trueswell's (2004) finding that children are only sensitive to linguistic but not extralinguistic context for disambiguating sentences, while adults are sensitive to both cues. They suggest that children commit to one analysis of the sentence and plan their actions during the early stages of sentence processing, when lexical information is more potent than referential cues, and are then unable to revise these plans in light of information about referential context. The central argument, as we see it, is thus not about the type of information children can or cannot use (linguistic vs. extralinguistic), but about the timeline of processing, whereby prior lexical 
information is available and salient early on, and children cannot flexibly adapt to new information that becomes available later in processing. Here we find that children show flexible adaptation, that is, they do not only rely on lifelong prior linguistic knowledge as in Snedeker and Trueswell's experiment. On the other hand our cues were linguistic in nature, so they might fit with Snedeker and Trueswell's finding that only linguistic and not extralinguistic information affects children's interpretations. Overall, we do not think our findings contradict Snedeker and Trueswell's explanation of their results, because we can think of three (non-mutually-exclusive) reasons why we did find priming in children's interpretation despite the fact that children of this age may find it hard to revise their interpretations. First, because the target trial shares the same verb with the prime sentence, it could be that the kids are still scaffolding parsing largely on lexical information. However, as stated above, the cumulative priming effect we find speaks to the fact that children do show at least some exposure-based learning of structure, which is separate from immediatepriming effects. Second, we suggest that the prime sentence induces a change in children's preferences that happens before their selection of response. Thus, finding an effect of the previous sentences in the experiment is in line with Snedeker and Trueswell's proposal that for children, early-available information is crucial in interpretation, while revision is harder. That is, information about previous sentences is available early in processing, while information about extralinguistic context is late-arriving. Our suggestion is in line with error-driven learning models (e.g., Chang, Dell \& Bock, 2006; Chang, Dell, Bock, \& Griffin, 2000; Reitter, Keller, \& Moore, 2011) which suggest that the processing of a prime sentence triggers changes to the underlying model a language user relies on for language processing. The changes induced by the prime sentence will have then taken place when comprehending the prime sentence and before the introduction of the target sentence, and therefore do not contradict Snedeker and Trueswell's (2004) suggestion.

Another reason, which was mentioned above, as to why we did find a priming effect might be related to the implementation of a touch-screen protocol. The tablet interface might encourage children to carefully examine the scene before touching the tablet to make their choice. A recent study compared three techniques (looking, pointing, and touching) with comparable materials, and concluded that a tablet-based paradigm compared favorably with an eye-tracking and a story-book paradigm in the context of word-recognition (Frank, Sugarman, Horowitz, Lewis, \& Yurovsky, 2016). Additionally, it also found that more children finished the task when it was on a tablet. 
Similarly, we had no participant drop out, despite the length of the task (about 25 minutes). This fun and portable low-cost setup can thus be used in further research investigating diverse processes of language acquisition.

Recent experience is not the only source of disambiguating information available. Factors like prosody can also affect the preference of one structure over the other. In the current study, prosody was meant to allow for both possible interpretations by using one intonation contour for the entire sentence. It has previously been shown that whereas the presence of acoustic boundary cues in two-phrase-prosody sentences results mostly in a two-phrase grouping (a noun-attachment interpretation), the absence of acoustic boundary cues does not necessarily result in a one-phrase grouping (a verb-attachment interpretation, Meyer, Henry, Gaston, Schmuck, \& Friederici, 2016). For example, [the girl is tickling] [the baby with the feather] would be more likely to be interpreted as a noun-attachment than [the girl is tickling the baby with a feather] which is more ambiguous. When there is only one prosodic unit, then, participants recruit other sources of information to disambiguate (see Meyer et al, 2016) - in our case these other sources of information would be both recent and long-term experience.

This is the first study showing clear priming of interpretations of globally ambiguous sentences in both adults and children. We found that already at 5-6 years of age children can be syntactically primed to choose different interpretations for the same globally-ambiguous sentence, and are sensitive to relative proportions of different structures in the input and to cumulative priming, just like adults. This suggests that adaptation to the proportion of structures in conversation is not a late emerging phenomenon, the result of a life-long expertise, but also exists in novice language users - though research on younger children is needed in order to better establish the developmental time-course of this ability.

\section{Acknowledgements}

We would like to thank Anne-Caroline Fiévet, our babylab manager for her help with recruitment and testing, and Marion Beretti and Alex de Carvalho for their help in testing. We thank Shravan Vasishth for statistical advice, Alex Cristia for allowing us to use the tablet application, Sharon Lim Sautarel for drawing the stimuli for the experiment, and the schools, parents and children for their collaboration. 
Funding: This work was supported by a postdoctoral grant to the first author from the French

Embassy in Israel and The Victor Smorgon Charitable Fund, and by the French Agence

Nationale de la Recherche (grants n ${ }^{\circ}$ ANR-13-APPR-0012 LangLearn, ANR-17-CE28-0007-01

LangAge, and ANR-17-EURE-0017 FrontCog).

\section{Disclosure of interest}

The authors report no conflict of interests 


\section{References}

Baayen, H., Bates, D., Kliegl, R., \& Vasishth, S. (2015). RePsychLing: Data sets from Psychology and Linguistics experiments. $\mathrm{R}$ package version 0.0.4.

Barr, D. J., Levy, R., Scheepers, C., \& Tily, H. J. (2013). Random effects structure for confirmatory hypothesis testing: Keep it maximal. Journal of Memory and Language, 68(3), 255-278. https://doi.org/10.1016/j.jml.2012.11.001

Bates, D., Kliegl, R., Vasishth, S., \& Baayen, H. (2015). Parsimonious mixed models. arXiv preprint arXiv:1506.04967.

Bates, D., Maechler, M., Bolker, B. \& Walker, S. (2015). Fitting Linear Mixed-Effects Models Using lme4. Journal of Statistical Software, 67, 1-48. doi:10.18637/jss.v067.i01.

Bock, K., \& Griffin, Z. M. (2000). The persistence of structural priming: Transient activation or implicit learning?. Journal of experimental psychology: General, 129(2), 177.

Boudewyn, M. A., Zirnstein, M., Swaab, T. Y., \& Traxler, M. J. (2014). Priming prepositional phrase attachment: evidence from eye-tracking and event-related potentials. Quarterly Journal of Experimental Psychology, 67(3), 424-54. https://doi.org/10.1080/17470218.2013.815237

Branigan, H. P., \& McLean, J. F. (2016). What children learn from adults' utterances: An ephemeral lexical boost and persistent syntactic priming in adult-child dialogue. Journal of Memory and Language, 91, 141-157.

Brandt, S., Nitschke, S., \& Kidd, E. (2017). Priming the Comprehension of German Object Relative Clauses Priming the Comprehension of German Object Relative Clauses. Language Learning and Development, 5441(March). https://doi.org/10.1080/15475441.2016.1235500

Branigan, H. P., McLean, J. F., \& Jones, M. (2005). A blue cat or a cat that is blue? - Evidence for abstract syntax in young children's noun phrases. Proceedings of the 29th Annual Boston University Conferece on Language Development, Vol. 1 and 2. pp. 109-121, Boston, MA.

Branigan, H. P., Pickering, M. J., \& McLean, J. F. (2005). Priming prepositional-phrase attachment during comprehension. Journal of Experimental Psychology. Learning, Memory, and Cognition, 31(3), 468-481. https://doi.org/10.1037/0278-7393.31.3.468

Brooks, P. A., \& Tomasello, M. (1999). Young children learn to produce passives with nonce verbs. Developmental Psychology, 35,29-44.

Cleland, A. A., \& Pickering, M. J. (2003). The use of lexical and syntactic information in language production: Evidence from the priming of noun-phrase structure. Journal of Memory and Language, 49(2), 214-230. doi:10.1016/S0749-596X(03)00060-3

de Carvalho, A., Dautriche, I., Lin, I., \& Christophe, A. (2017). Phrasal prosody constrains syntactic analysis in toddlers. Cognition, 163, 67-79. https://doi.org/10.1016/j.cognition.2017.02.018

Chang, F., Dell, G. S., \& Bock, K. (2006). Becoming syntactic. Psychological Review, 113(2), 234-272. https://doi.org/10.1037/0033-295X.113.2.234

Chang, F., Dell, G. S., Bock, K., \& Griffin, Z. M. (2000). Structural priming as implicit learning: A comparison of models of sentence production. Journal of psycholinguistic research, 29(2), 217-230.

Frank, M. C., Sugarman, E., Horowitz, A. C., Lewis, M. L., \& Yurovsky, D. (2016). Using Tablets to Collect Data from Young Children, Journal of Cognition and 
Development, 17(1), 1-17. https://doi.org/10.1080/15248372.2015.1061528

Gibson, E., \& Pearlmutter, N. J. (1998). Constraints on sentence comprehension, Trends in cognitive sciences, 2(7), 262-268.

Havron, N., de Carvalho, A., Fiévet, A., \& Christophe, A. (2019). Three- to Four-Year-Old Children Rapidly Adapt Their Predictions and Use Them to Learn Novel Word Meanings.

Child Development, 1-9. https://doi.org/10.1111/cdev.13113

Jaeger, T. F., \& Snider, N. E. (2013). Alignment as a consequence of expectation adaptation: Syntactic priming is affected by the prime's prediction error given both prior and recent experience. Cognition, 127(1), 57-83. https://doi.org/10.1016/j.cognition.2012.10.013

Kidd, E., \& Holler, J. (2009). Children's use of gesture to resolve lexical ambiguity. Developmental Science, 12(6), 903-913. https://doi.org/10.1111/j.14677687.2009.00830.x

Kaschak, M. P., Kutta, T. J., \& Jones, J. L. (2011). Structural Priming as Implicit Learning: Cumulative Priming Effects and Individual Differences. Psychonomic Bulletin \& Review, 18(6), 1133-1139. https://doi.org/10.14440/jbm.2015.54.A

Kaschak, M. P., Kutta, T. J., \& Schatschneider, C. (2011). Long-term cumulative structural priming persists for (at least) one week, Memory \& Cognition, 39, 381-388. https://doi.org/10.3758/s13421-010-0042-3

Kuznetsova A., Brockhoff P.B. \& Christensen, R.H.B (2017). lmerTest Package: Tests in Linear Mixed Effects Models. Journal of Statistical Software, 82(13), 1-26. http://doi.org/10.18637/jss.v082.i13

Lin, Y., Fisher, C. (2017). Error-Based Learning: A Mechanism for Linking Verbs to Syntax, proceedings of CogSci, London, UK (pp 754-759).

MacDonald, M. C., Pearlmutter, N. J., \& Seidenberg, M. S. (1994). The lexical nature of syntactic ambiguity resolution. Psychological Review, 101(4), 676-703.

Mahowald, K., James, A., Futrell, R., \& Gibson, E. (2015). A meta-analysis of syntactic priming in language production. Journal of Memory and Language, 91, 5-27. https://doi.org/10.1016/j.jml.2016.03.009

Messenger, K., Branigan, H. P., McLean, J. F., \& Sorace, A. (2012). Is young children's passive syntax semantically constrained? Evidence from syntactic priming. Journal of Memory and Language, 66(4), 568-587. https://doi.org/10.1016/j.jml.2012.03.008

Meyer, L., Henry, M. J., Gaston, P., Schmuck, N., \& Friederici, A. D. (2016). Linguistic Bias Modulates Interpretation of Speech via Neural Delta-Band Oscillations. Cerebral Cortex, 27(9), 4293-4302. https://doi.org/10.1093/cercor/bhw228

Morris, L. C., \& Scheepers, C. (2015). Syntactic priming and the lexical boost in preschool children. Open access manuscript.

Peter, M., Chang, F., Pine, J. M., Blything, R., \& Rowland, C. F. (2015). When and how do children develop knowledge of verb argument structure? Evidence from verb bias effects in a structural priming task. Journal of Memory and Language, 81(December), 1-15. https://doi.org/10.1016/j.jml.2014.12.002

Pickering, M. J., \& Garrod, S. (2013). An integrated theory of language production and comprehension. Behavioral and Brain Sciences, 36, 329-392. https://doi.org/10.1017/S0140525X12001495

Qi, Z., Yuan, S., \& Fisher, C. (2011) Where does Verb Bias Come From? Experience with Particular Verbs Affects Online Sentence Processing. Proceedings of the 35th Annual Boston 
University Conference on Language Development (pp. 500-512). Boston, MA: Cascadilla Press.

R Core Team (2017). R: A language and environment for statistical computing. $R$ Foundation for Statistical Computing, Vienna, Austria. URL https://www.R-project.org/.

Reitter, D., Keller, F., \& Moore, J. D. (2011). A Computational Cognitive Model of Syntactic Priming. Cognitive Science, 35(4), 587-637. https://doi.org/10.1111/j.15516709.2010.01165.x

Rowland, C. F., Chang, F., Ambridge, B., Pine, J. M., \& Lieven, E. V. M. (2012). The development of abstract syntax: Evidence from structural priming and the lexical boost. Cognition, 125(1), 49-63. https://doi.org/10.1016/j.cognition.2012.06.008

Shimpi, P. M., Gámez, P. B., Huttenlocher, J., \& Vasilyeva, M. (2007). Syntactic priming in 3and 4-year-old children: evidence for abstract representations of transitive and dative forms. Developmental Psychology, 43(6), 1334-1346. https://doi.org/10.1037/00121649.43.6.1334

Snedeker, J. \& Thothathiri, M. (2008). What Lurks Beneath: Syntactic Priming During Language Comprehension in Preschoolers (and Adults). In E. Sekerina, Fernández, \& H. Clahsen (Eds.), Developmental Psycholinguistics: On-Line Methods in Children's Language Processing (pp. 251-315). Amsterdam: Benjamins.

Snedeker, J., \& Trueswell, J. C. (2004). The developing constraints on parsing decisions: The role of lexical-biases and referential scenes in child and adult sentence processing. Cognitive Psychology, 49(3), 238-299. https://doi.org/10.1016/j.cogpsych.2004.03.001

Snedeker, J., \& Yuan, S. (2008). Effects of prosodic and lexical constraints on parsing in young children (and adults). Journal of Memory and Language, 58(2), 574-608. https://doi.org/10.1016/j.jml.2007.08.001

Thothathiri, M., \& Snedeker, J. (2008). Syntactic priming during language comprehension in three-and four-year-old children. Journal of Memory and Language, 58, 188-213

Traxler, M. J. (2002). Plausibility and subcategorization preference in children's processing of temporarily ambiguous sentences: Evidence from self-paced reading, The Quarterly Journal of Experimental Psychology, 55(1), 75-96. https://doi.org/10.1080/0272498014300017

Weighall, A. R. (2008). The kindergarten path effect revisited: Children's use of context in processing structural ambiguities. Journal of Experimental Child Psychology, 99(2), 75-95. https://doi.org/10.1016/j.jecp.2007.10.004

Wickham, H. (2016). ggplot2: Elegant Graphics for Data Analysis. Springer-Verlag, New York. Zimmer, E. J. (2017). Children's comprehension of two types of syntactic ambiguity. First Language, 37(1), 7-23. https://doi.org/10.1177/0142723716673952 


\section{Appendix 1: stimuli}

\begin{tabular}{|c|c|c|c|}
\hline id & Sentence & & verb \\
\hline 1 & Le garçon fait un bisou à la fille avec son doudou & The boy is kissing the girl with her/his teddy-bear & fait un bisou \\
\hline 2 & Le prince fait un bisou à la princesse avec la peluche & The prince is kissing the princess with the dolly & fait un bisou \\
\hline 3 & Le garçon bouscule la fille avec la trottinette & The boy is pushing the girl with the scooter & bouscule \\
\hline 4 & Le prince bouscule la princesse avec le vélo & The prince is pushing the princess with the bike & bouscule \\
\hline 5 & Le singe chatouille la grenouille avec la plume & The monkey is tickling the frog with the feather & chatouille \\
\hline 6 & La fille chatouille le bébé avec le pinceau & The girl is tickling the baby with the paint brush & chatouille \\
\hline 7 & Le chat tape la souris avec le fromage & The cat is hitting the mouse with the cheese & tape \\
\hline 8 & Le singe tape la grenouille avec le bâton & The monkey is hitting the frog with the branch & tape \\
\hline 9 & La dame envoie la lettre avec le pigeon & The lady is sending the letter with the pigeon & envoie \\
\hline 10 & Le garçon envoie le message avec la flèche & The boy is sending the message with the arrow & envoie \\
\hline 11 & Le garçon touche la fille avec le parapluie & The boy is touching the girl with the umbrella & touche \\
\hline 12 & Le singe touche la grenouille avec un balai & The monkey is touching the frog with the broom & touche \\
\hline 13 & Le garçon regarde la fille avec les jumelles & The boy is looking at the girl with the binoculars & regarde \\
\hline & & The king is looking at the queen with the & \\
\hline 14 & Le roi regarde la reine avec la loupe & magnifying glass & regarde \\
\hline 15 & Le garçon tire le chat avec la laisse & The boy is pulling the cat with the leash & tire \\
\hline 16 & La fille tire le cheval avec la corde & The girl is pulling the horse with the rope & tire \\
\hline 17 & La fille lave le chien avec une éponge & The girl is washing the dog with a sponge & lave \\
\hline 18 & Le garçon lave le cheval avec une brosse & The boy is washing the horse with a brush & lave \\
\hline 19 & Le garçon caresse la fille avec une plume & The boy is stroking the girl with a feather & caresse \\
\hline 20 & La fille caresse le chat avec le pinceau & The girl is stroking the cat with the paint brush & caresse \\
\hline 21 & Le garçon pousse la fille avec un carton & The boy is pushing the girl with a cardboard box & pousse \\
\hline 22 & Le roi pousse la reine avec le balai & The king is pushing the queen with the broom & pousse \\
\hline
\end{tabular}

